\title{
Atomic layer deposition of aluminium phosphate based on the plasma polymerization of trimethyl
}

\section{phosphate}

Thomas Dobbelaere, ${ }^{\dagger},{ }^{\top}$ Amit K. Roy, ${ }^{\dagger} \uparrow$ Philippe Vereecken, ${ }^{\ddagger}$ and Christophe

\section{Detavernier*,}

Department of Solid State Sciences, Ghent University, Krijgslaan 281 S1, 9000 Gent, Belgium, and IMEC, Kapeldreef 75, 3001 Leuven, Belgium

E-mail: christophe.detavernier@ugent.be

\begin{abstract}
Aluminium phosphate thin films were deposited by plasma-assisted atomic layer deposition (ALD) using a sequence of trimethyl phosphate (TMP, $\mathrm{Me}_{3} \mathrm{PO}_{4}$ ) plasma, $\mathrm{O}_{2}$ plasma and trimethylaluminium ( $\mathrm{TMA}, \mathrm{Me}_{3} \mathrm{Al}$ ) exposures. In-situ characterization was performed, including spectroscopic ellipsometry, optical emission spectroscopy, mass spectrometry and FTIR. In the investigated temperature region between $50{ }^{\circ} \mathrm{C}$ and $320{ }^{\circ} \mathrm{C}$, nucleation delays were absent and linear growth was observed, with the growth per cycle (GPC) being strongly dependent on temperature. The plasma polymerization of TMP was found to play an important role in this process, resulting in CVD-like behavior at low temperatures and ALD-like behavior at high temperatures. Films grown at $320{ }^{\circ} \mathrm{C}$ had a GPC of $3.7 \AA /$ cycle and consisted of amorphous

* To whom correspondence should be addressed

${ }^{\dagger}$ Ghent University

"These authors contributed equally to this work
\end{abstract}

‡IMEC 
aluminium pyrophosphate $\left(\mathrm{Al}_{4} \mathrm{P}_{6} \mathrm{O}_{21}\right)$. They could be crystallized to triclinic $\mathrm{AlPO}_{4}$ tridymite by annealing to $900{ }^{\circ} \mathrm{C}$, as evidenced by high temperature XRD measurements. The use of a TMP plasma might open up the possibility of depositing many other metal phosphates by combining it with appropriate organometallic precursors.

\section{Introduction}

Atomic layer deposition (ALD) is a thin film deposition technique in which layer-by-layer growth is achieved through alternating exposures to chemical vapors. It can be seen as a special form of chemical vapor deposition (CVD) where the precursor exposures are separated in sequential, self-limiting half reactions. Many classes of materials have been deposited by ALD processes, including various oxides, II-VI and III-V semiconductors, metal nitrides, metals, metal sulfides, and fluorides. ${ }^{1}$ Reports on the atomic layer deposition of phosphates are still scarce, but seem to be gaining popularity over the last years. Table 1 presents a summary of the existing literature on this subject.

Phosphate ALD processes have been developed targeting a wide range of applications: aluminium phosphate as a catalyst support, ${ }^{2}$ as an ion barrier in electroluminescent displays, ${ }^{3}$ to improve lithium-ion battery cathodes, ${ }^{12}$ as a transistor gate dielectric, ${ }^{13}$ and to improve the oxidation resistance of carbon fibers; ${ }^{9}$ calcium phosphate (hydroxyapatite) for biomedical applications; ${ }^{4}$ titanium phosphate for its ion-exchange properties ${ }^{14}$ and for its catalytic activity; ${ }^{15}$ iron phosphate as a cathode material ${ }^{10}$ and lithium phosphate as a solid-state electrolyte ${ }^{16}$ for lithium-ion batteries.

These processes are typically based on the inclusion of a phosphorus source in an existing

metal oxide ALD process. In theory, phosphoric acid $\left(\mathrm{H}_{3} \mathrm{PO}_{4}\right)$ would be an ideal candidate for this, but its use in vapor deposition is prohibited by its low vapor pressure at room temperature and its tendency to decompose rather than evaporate upon heating. Phosphorus pentoxide $\left(\mathrm{P}_{2} \mathrm{O}_{5}\right)$ can be used, but needs to be heated to $170{ }^{\circ} \mathrm{C}$ or higher; ${ }^{2,3}$ this presents challenges to the reactor design. Trimethyl phosphate (TMP, $\mathrm{Me}_{3} \mathrm{PO}_{4}$ ) is an attractive 
Table 1: Overview of earlier work on the atomic layer deposition of phosphates.

\begin{tabular}{|c|c|c|c|c|c|}
\hline $\begin{array}{l}\text { Authors } \\
\text { (Year) }\end{array}$ & Metal (source) & $\begin{array}{l}\text { Phosphorus } \\
\text { source }\end{array}$ & $\begin{array}{l}\text { Temperature } \\
\left({ }^{\circ} \mathrm{C}\right)\end{array}$ & GPC $(\AA)$ & $\operatorname{GPSS}(\AA)^{a}$ \\
\hline $\begin{array}{l}\text { Nieminen } \\
\text { et al. }(1995)^{2}\end{array}$ & $\begin{array}{l}\text { Aluminium } \\
\text { (trichloride) }\end{array}$ & $\begin{array}{l}\mathrm{P}_{2} \mathrm{O}_{5} \\
\text { TMP }\end{array}$ & 500 & N.A. & N.A. \\
\hline $\begin{array}{l}\text { Tiitta } \\
\text { et al. }(1998)^{3}\end{array}$ & $\begin{array}{l}\text { Aluminium } \\
\text { (trichloride, } \\
\text { n-propoxide) }\end{array}$ & $\mathrm{P}_{2} \mathrm{O}_{5}$ & $450-500$ & $0.5-1.3$ & $0.3-0.6$ \\
\hline $\begin{array}{l}\text { Putkonen } \\
\text { et al. }(2009)^{4}\end{array}$ & Calcium $\left((\text { thd })_{2}\right)$ & TMP & 300 & 0.4 & 0.1 \\
\hline $\begin{array}{l}\text { Hämäläinen } \\
\text { et al. }(2012)^{5}\end{array}$ & $\begin{array}{l}\text { Lithium (hexa- } \\
\text { methyldisilazide) }\end{array}$ & TMP & $225-300$ & $0.7-1.0$ & $0.3-0.5$ \\
\hline $\begin{array}{l}\text { Hämäläinen } \\
\text { et al. }(2012)^{5}\end{array}$ & $\begin{array}{l}\text { Lithium (tert - } \\
\text { butoxide) }\end{array}$ & TMP & $275-350$ & $0.4-1.3$ & $0.2-0.7$ \\
\hline $\begin{array}{l}\text { Wiedmann } \\
\text { et al. }(2012)^{6}\end{array}$ & $\begin{array}{l}\text { Titanium } \\
\text { (tetrachloride) }\end{array}$ & TMP & $150-300$ & 1.2 & 0.3 \\
\hline $\begin{array}{l}\text { Hämäläinen } \\
\text { et al. }(2012)^{7}\end{array}$ & $\begin{array}{l}\text { Aluminium } \\
\text { (trichloride) }\end{array}$ & TMP & $150-400$ & $1.4-2.4$ & $0.7-1.2$ \\
\hline $\begin{array}{l}\text { Hämäläinen } \\
\text { et al. }(2012)^{7}\end{array}$ & $\begin{array}{l}\text { Titanium } \\
\text { (tetrachloride) }\end{array}$ & TMP & $275-450$ & $0.4-1.4$ & $0.2-0.7$ \\
\hline $\begin{array}{l}\text { Liu } \\
\text { et al. }(2013)^{8}\end{array}$ & $\begin{array}{l}\text { Aluminium } \\
\text { (trimethyl-) }\end{array}$ & TMP & 150 & 1.7 & 0.08 \\
\hline $\begin{array}{l}\text { Knohl } \\
\text { et al. }(2013)^{9}\end{array}$ & $\begin{array}{l}\text { Aluminium } \\
\text { (trimethyl-) }\end{array}$ & TEP & 250 & $0.8-1.3$ & $0.4-0.7$ \\
\hline $\begin{array}{l}\text { Gandrud } \\
\text { et al. }(2013)^{10}\end{array}$ & Iron $\left((\text { thd })_{3}\right)$ & TMP & $200-380$ & 1.0 & 0.05 \\
\hline $\begin{array}{l}\text { Sønsteby } \\
\text { et al. }(2014)^{11}\end{array}$ & $\begin{array}{l}\text { Lanthanum } \\
\left((\text { thd })_{3}\right)\end{array}$ & TMP & $250-300$ & 0.8 & 0.2 \\
\hline This work & $\begin{array}{l}\text { Aluminium } \\
\text { (trimethyl-) }\end{array}$ & $\begin{array}{l}\text { TMP } \\
\text { plasma }\end{array}$ & 320 & 3.7 & 1.2 \\
\hline
\end{tabular}

${ }^{a}$ Growth per substep $=($ growth per cycle $) /($ number of substeps in one cycle $)$ 
alternative: this organophosphate compound reaches a vapor pressure of 15 mbar at $70{ }^{\circ} \mathrm{C} .{ }^{17}$ Thermal ALD processes using TMP have been demonstrated for a variety of metal sources. Especially where chloride precursors were avoided, ${ }^{4,5,8-10}$ it has proven difficult to incorporate a sufficiently high atomic percentage of phosphorus in the growing film (presumably due to the low reactivity of TMP with organometallic compounds), unless one introduces a large number of phosphate subcycles for each metal pulse. This considerably slows down the growth; for this reason, table 1 not only lists the reported growth per cycle (GPC) but also the average growth per substep (calculated by dividing the GPC by the number of substeps in one cycle) in order to make a fair comparison between the expected deposition rates of different ALD chemistries.

In this work, the TMP precursor is used in a novel way: the vapor is brought into an inductively coupled plasma (ICP) discharge, and a TMP plasma is created. To the best of our knowledge, the use and/or properties of an inductively coupled plasma of low-pressure TMP vapor have not previously been reported in literature. Perhaps most closely related to this topic is the work by Hilt et al. ${ }^{18}$ wherein organophosphate coatings were deposited by an atmospheric-pressure plasma of triethyl phosphate (TEP), and a patent application by Zhang et al. ${ }^{19}$ which describes the deposition of lithium-containing solid electrolyte films by mixing a volatile lithium precursor and a volatile phosphate precursor (TMP or TEP) into a low-pressure nitrogen/hydrogen plasma. The use of plasma greatly increases the reactivity of TMP and its tendency to introduce phosphorus into the deposited film. By alternating TMP plasma pulses with $\mathrm{O}_{2}$ plasma and TMA exposures in an ALD-type process, we are able to grow thin films of aluminium phosphate with a high growth rate and with precise thickness control. 


\section{Experimental}

Depositions were carried out in a home-built pump-type ALD reactor, shown schematically in figure 1. The stainless steel deposition chamber was continuously evacuated by a turbomolecular pump to a base pressure in the $10^{-6}$ mbar range. Precursor vapors and gases were admitted through computer-controlled pneumatic valves and manually adjustable needle valves. The TMP precursor was heated in a stainless steel container to $68^{\circ} \mathrm{C}$, while the tube leading to the reactor was kept at $70^{\circ} \mathrm{C}$. The TMA precursor was used at room temperature. The temperature of the chamber walls was set to $95^{\circ} \mathrm{C}$. On top of the chamber, a gate valve leads to a fused quartz column wrapped by a copper coil. The coil is connected to a 13.56 MHz RF generator (Advanced Energy CESAR 136) and a matching network in order to generate an inductively coupled plasma in the column. By opening the gate valve and pulsing the RF generator, substrates could be exposed to remote plasma. The TMP plasma was created by feeding TMP vapor from the chamber through the gate valve, while for the oxygen plasma the $\mathrm{O}_{2}$ gas was injected directly into the column. The plasma power was set to $100 \mathrm{~W}$ and the impedance matching parameters were tuned to minimize the reflected power. All gas flows (TMP, TMA and oxygen) were adjusted to reach a partial pressure of $6 \times 10^{-3}$ mbar in the deposition chamber. All substrates were pieces of standard p-type silicon (100) wafer cut to size; for in-situ FTIR measurements in transmission mode, the double

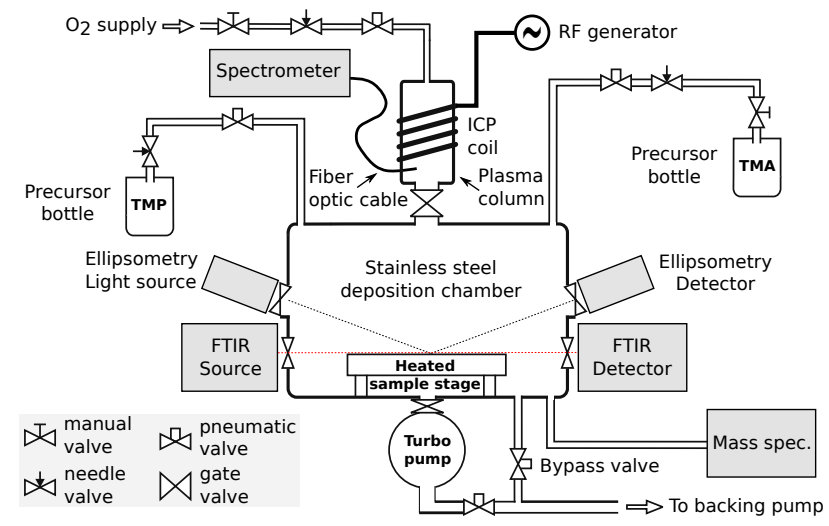

Figure 1: Schematic drawing of the deposition system used in this work, along with the in-situ characterization options. 
polished variety was used. They were mounted to a molybdenum sample holder which rested on a heated copper block. The temperature of the copper block was PID controlled, and sample temperatures were calculated from copper block temperatures by calibration.

In-situ spectroscopic ellipsometry measurements were performed with a J.A. Woollam M-2000 ellipsometer working in the ultraviolet-visible region and using the CompleteEASE software for fitting and data analysis. The optical model always consisted of a silicon substrate covered by a single layer which satisfied a Cauchy dispersion relation; coefficients were determined from layers with a known thickness (aided by XRR) and were held fixed, while the thickness (as the only free parameter) was fitted in situ. Optical emission spectra were recorded with an Ocean Optics QE Pro spectrometer coupled to the plasma column by an optical fiber. Mass spectrometry was carried out with a Hiden HPR-30 mass spectrometer using $70 \mathrm{eV}$ electron impact ionization and a quadrupole mass filter combined with a Faraday detector. Infrared spectroscopy was performed on a Bruker VERTEX 70V FTIR spectrometer with $\mathrm{KBr}$ beamsplitter and an $\mathrm{LN}_{2}$-cooled MCT detector (mid-infrared). XRR and XRD patterns were acquired on a Bruker D8 diffractometer using $\mathrm{Cu} \mathrm{K} \alpha$ radiation; in-situ annealing was performed in a home-built chamber under a helium atmosphere using a position sensitive detector. Energy-dispersive X-ray spectroscopy (EDX) was carried out in an FEI Quanta $200 \mathrm{~F}$ scanning electron microscope using a $10 \mathrm{keV}$ electron beam and an EDAX silicon-drift detector. X-ray Photoelectron Spectroscopy (XPS) analysis was performed on a Thermo Scientific Theta Probe XPS instrument using Al K $\alpha$ X-rays generated at $15 \mathrm{kV}$ and $70 \mathrm{~W}$ and focused to a spot size of $0.3 \mathrm{~mm}$ by an MXR1 monochromator gun. The sample surface was etched by $\mathrm{Ar}^{+}$ions at an acceleration voltage of $3 \mathrm{keV}$ and a current of $2 \mu \mathrm{A}$. The elastic recoil detection (ERD) measurements were carried out using a $10 \mathrm{MeV}{ }^{63} \mathrm{Cu}^{5+}$ beam, with a scattering angle of $40^{\circ}$ and a sample tilt of $20^{\circ}$. 


\section{Results and discussion}

\section{TMP plasma properties}

To start, we will focus on the TMP plasma, which is the first step in the proposed ALD process. Figure 2 shows the optical emission spectrum of this plasma in the visible range. To the naked eye, its color appears bluish white. The spectrum contains atomic emission lines of hydrogen (Balmer series: $\mathrm{H}_{\alpha}$ at $656.3 \mathrm{~nm}, \mathrm{H}_{\beta}$ at $486.1 \mathrm{~nm}$ and $\mathrm{H}_{\gamma}$ at $434.0 \mathrm{~nm}$ ) and oxygen (O I triplet around $777.4 \mathrm{~nm}$ ) in addition to a molecular band structure which could not be identified from literature but which is thought to arise from transitions between molecular energy levels in the (charged) TMP molecule and/or fragments of it.

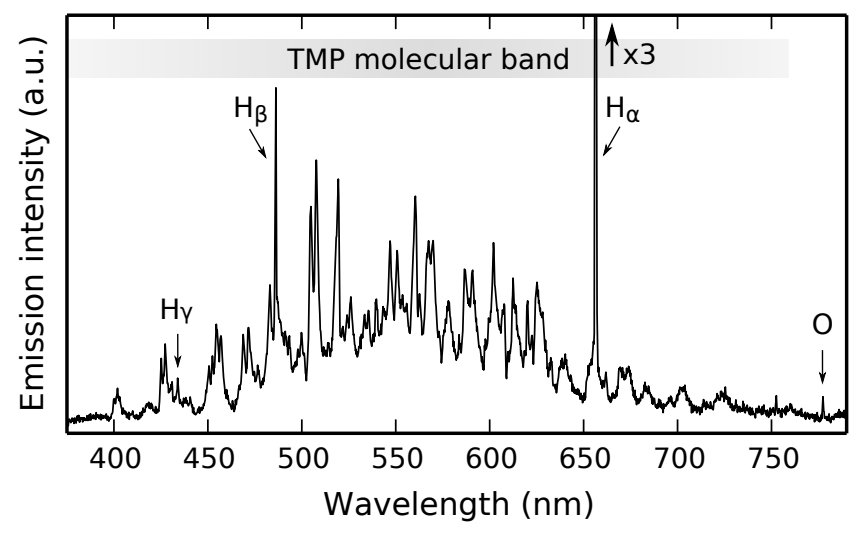

Figure 2: The optical emission spectrum of a 100W inductively coupled TMP plasma between $375 \mathrm{~nm}$ and $790 \mathrm{~nm}$. Hydrogen and oxygen atomic emission lines are superimposed on the molecular band spectrum.

To further investigate what makes up this plasma, the mass spectra of TMP vapor and TMP plasma were compared. The results are shown in figure 3. While the spectrometer measured masses between 1 and 300 atomic mass units (amu), figure 3 only shows masses up to 150 amu because no heavier species were detected.

The upper and lower graphs are largely identical; even as vapor, TMP is broken up into many fragments by electron impact ionization in the spectrometer. One could expect the plasma to do the same thing, but it is not possible to distinguish this from fragmentation in the instrument. However, upon close inspection, some differences due to the plasma 


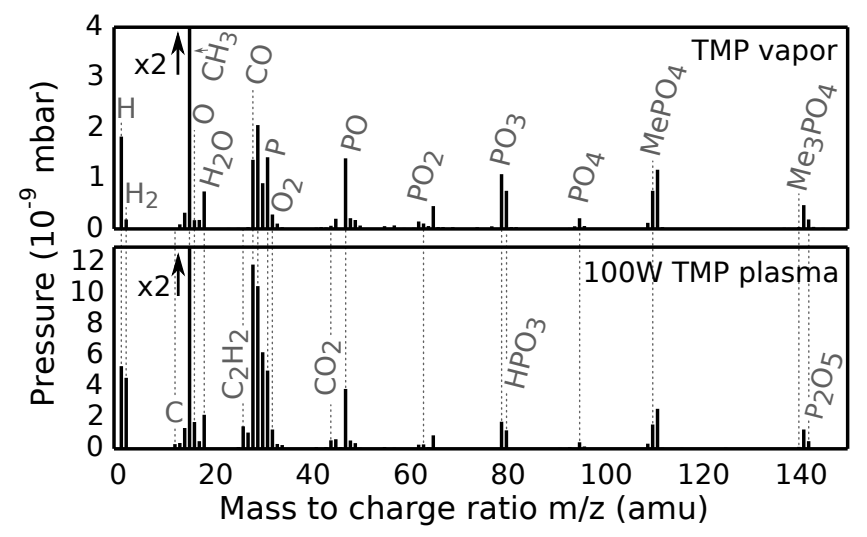

Figure 3: Mass spectra of TMP vapor (upper graph) and TMP plasma (lower graph) between 1 and $150 \mathrm{amu}$. Selected peaks are labeled with their corresponding fragment structures.

are visible. Most notable is the formation of $\mathrm{H}_{2}$ (hydrogen gas), witnessed by a significant increase at $\mathrm{m} / \mathrm{z}=2$. This is obviously related to the strong hydrogen emission lines in OES. Other appearances include elemental carbon at $\mathrm{m} / \mathrm{z}=12, \mathrm{C}_{2} \mathrm{H}_{2}$ (acetylene) at $\mathrm{m} / \mathrm{z}=26$, $\mathrm{C}_{2} \mathrm{H}_{3}$ at $\mathrm{m} / \mathrm{z}=27$ and $\mathrm{CO}_{2}$ at $\mathrm{m} / \mathrm{z}=44$. The increase at $\mathrm{m} / \mathrm{z}=16$ could be attributed to contributions from either atomic oxygen or $\mathrm{CH}_{4}$ (methane), but the presence of the atomic oxygen emission line in the optical spectrum makes the former option the most likely one.

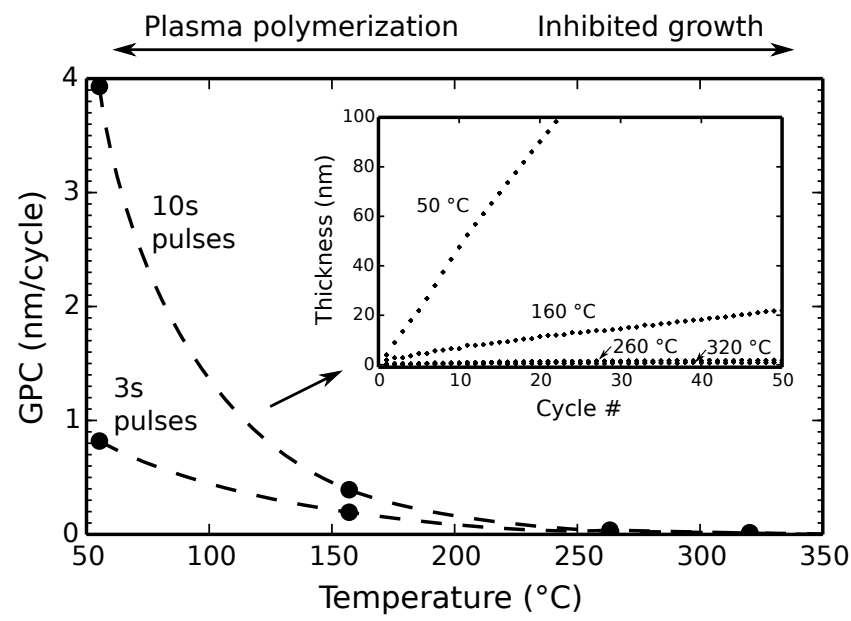

Figure 4: The growth per cycle as a function of the deposition temperature for sequences consisting of $3 \mathrm{~s}$ and $10 \mathrm{~s}$ TMP plasma pulses. Inset: growth curves measured by in-situ ellipsometry for 10 s TMP plasma pulses, showing linear growth. 


\section{TMP plasma polymerization}

It was observed that material got deposited onto substrates by exposure to this remote TMP plasma. Figure 4 shows the result of exposing a substrate to a sequence of TMP plasma pulses at different temperatures while monitoring the growth using in-situ ellipsometry. The Cauchy dispersion relation for these layers was $n(\lambda)=1.454+5.30 \times 10^{-3} \mu \mathrm{m}^{2} / \lambda^{2}-7.82 \times$ $10^{-5} \mu \mathrm{m}^{4} / \lambda^{4}$, yielding a refractive index of 1.47 at a wavelength of $589 \mathrm{~nm}$. Two pulse lengths had been chosen, namely $3 \mathrm{~s}$ and $10 \mathrm{~s}$. At low temperatures, a large amount of material was being deposited, and the amount increased with the TMP plasma pulse length. This suggests a continuous, CVD-like deposition process. However, at higher temperatures, the deposition rate dropped spectacularly and the process was almost totally inhibited.

The formation of a solid deposit by a plasma discharge is generally known as plasma polymerization. The growth rates of such processes often show a strong temperature dependency. In particular, the growth rate vs. temperature plot of the plasma polymerization of tetrafluoroethylene ${ }^{20}$ looks very similar to the curve in figure 4 . This can be understood from thermodynamic arguments: whether the polymerization reaction proceeds is determined by the change in Gibbs free energy $\Delta G=\Delta H-T \Delta S$, where $\Delta H$ represents the reaction enthalpy and $\Delta S$ the change in entropy. The reaction will only proceed if $\Delta G<0$. As $\Delta H<0$ (the formation of new chemical bonds in the solid deposit is energetically favorable) but also $\Delta S<0$ (the gas $\rightarrow$ solid transition results in increased order and thus decreased entropy), $\Delta G<0$ for sufficiently small $\mathrm{T}$. However, as $\Delta G$ increases with temperature, there will be a temperature above which $\Delta G>0$ and the polymerization reaction no longer takes place. In other words, there is a ceiling temperature above which the polymerization reaction is inhibited. Another piece of evidence to support our argument is the formation of hydrogen gas in the plasma by the release of hydrogen from $\mathrm{C}-\mathrm{H}$ bonds, in this case witnessed by mass spectrometry and OES, and as frequently encountered in the plasma polymerization of hydrocarbons. ${ }^{20}$ We therefore identify this process step as the plasma polymerization of TMP, with a ceiling temperature in the vicinity of $300{ }^{\circ} \mathrm{C}$. 
The chemical nature of the deposited layer was further investigated by in-situ FTIR as shown in figure 5. For reference purposes, the absorption spectrum of TMP vapor was separately measured and included in the same figure. In this spectrum, peaks at 2960, 2860 and $2350 \mathrm{~cm}^{-1}$ can be attributed to various $\mathrm{C}-\mathrm{H}$ stretching vibrations of methyl groups in the TMP molecule, while a $\mathrm{P}=\mathrm{O}$ stretch can be identified around $1300 \mathrm{~cm}^{-1}$, a $\mathrm{CH}_{3}$ rocking vibration at $1190 \mathrm{~cm}^{-1}$, a $(\mathrm{P})-\mathrm{O}-\mathrm{C}$ stretch at $1060 \mathrm{~cm}^{-1}$, and a $\mathrm{P}-\mathrm{O}-(\mathrm{C})$ stretch at $850 \mathrm{~cm}^{-1} \cdot{ }^{21,22}$ During deposition, absorption spectra of the deposited material were measured in-situ at a substrate temperature of $150{ }^{\circ} \mathrm{C}$; the sample was exposed to TMP plasma for 120 s between two consecutive measurements. The infrared absorbance grows progressively stronger over time, which is in agreement with the linear growth evidenced earlier by in-situ ellipsometry, confirming the continuous deposition of material at this temperature. Several absorption peaks coincide with the TMP vapor reference spectrum, which suggests that the solid deposit is chemically similar to TMP. However, the peaks are heavily broadened, and in particular a new structure consisting of three very broad bands around $2700 \mathrm{~cm}^{-1}, 2200 \mathrm{~cm}^{-1}$ and $1600 \mathrm{~cm}^{-1}$ can be observed. This is a so-called ABC structure, which typically arises from $\mathrm{O}-\mathrm{H}$ stretching vibrations in strongly hydrogen bonded complexes; in particular, the observed $\mathrm{O}-\mathrm{H}$ band structure is very similar to the one encountered for dimethylphosphinic acid $\left(\left(\mathrm{CH}_{3}\right)_{2} \mathrm{POOH}\right)$ in the solid state. ${ }^{23}$ This implies that some of the $-\mathrm{O}-\mathrm{CH}_{3}$ groups in

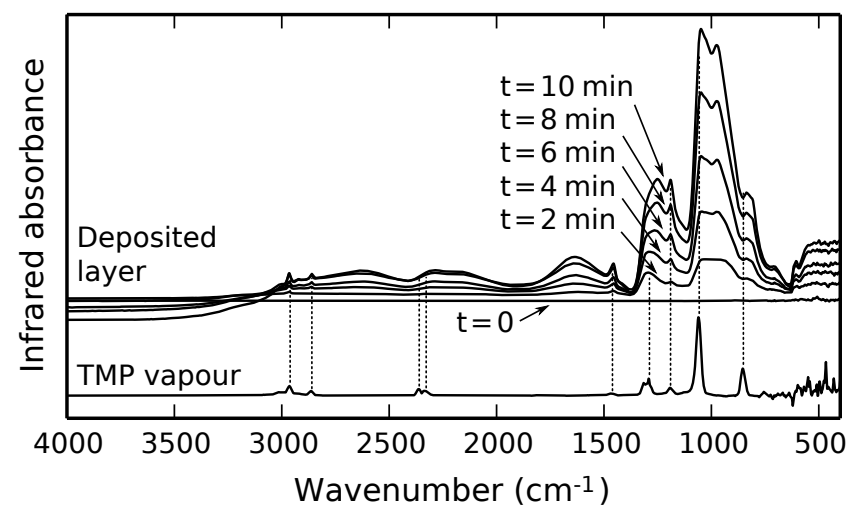

Figure 5: In-situ FTIR during TMP plasma polymerization at a substrate temperature of $150{ }^{\circ} \mathrm{C}$, along with the absorption spectrum of TMP vapor. 
the TMP precursor are being converted to $-\mathrm{OH}$ groups during the plasma polymerization process, and the resulting deposited layers are presumably mixtures of phosphate esters.

The layers resulting from TMP plasma polymerization were closed films when inspected immediately after removal from the reactor, but film degradation became visible after a few hours of exposure to an ambient atmosphere. This suggests a reaction of the deposited material with ambient oxygen and/or water vapor. After a few weeks, some samples in particular started to show fractal-like dendritic structures. This reactivity might be related to the high amount of free radicals which are typically embedded in plasma-polymerized films. ${ }^{20}$

\section{Further oxidation by $\mathrm{O}_{2}$ plasma}

Freshly deposited samples were brought into a scanning electron microscope for EDX analysis. The results are shown in figure 6. Layers deposited by the TMP plasma contained oxygen, phosphorus and carbon, as shown by curve (a); we can thus refer to them as organophosphate coatings. When one wants to grow metal phosphates, however, carbon is an undesirable contaminant in the final layer. An additional oxygen plasma exposure was

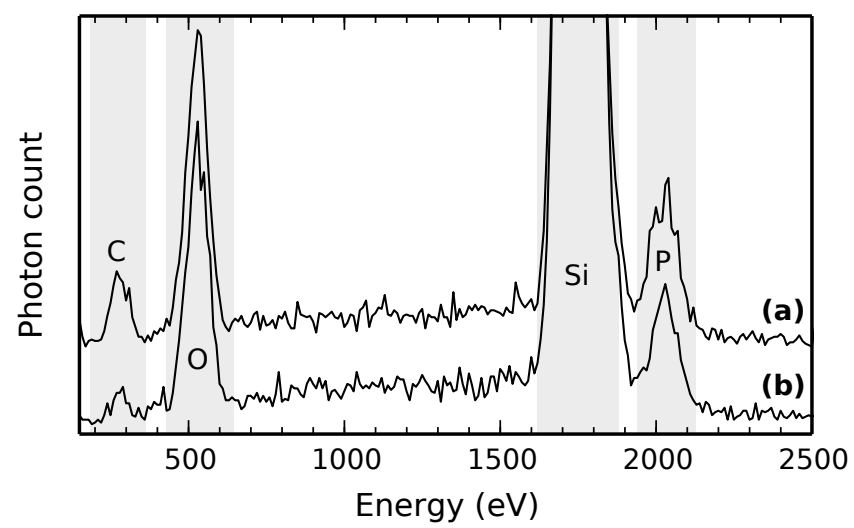

Figure 6: Energy-dispersive X-ray spectroscopy of phosphate films grown on silicon substrates by TMP plasma polymerization at $150{ }^{\circ} \mathrm{C}$. Peaks at the characteristic X-ray K-lines of $\mathrm{C}, \mathrm{O}, \mathrm{Si}$ and $\mathrm{P}$ are indicated. Curve (a) corresponds to a layer grown by 400 cycles of $3 \mathrm{~s}$ TMP plasma, while curve (b) is the result of $400 \times\left[3 \mathrm{~s}\right.$ TMP plasma $-3 \mathrm{~s} \mathrm{O}_{2}$ plasma $]$ and contains a significantly lower amount of carbon. 
therefore introduced after each TMP plasma step in order to remove carbon by combustion. The effectiveness of this step is illustrated by curve (b) in figure 6, which shows that the amounts of phosphorus and oxygen remain the same but the amount of carbon is significantly reduced. The oxygen plasma presumably converts remaining $-\mathrm{O}-\mathrm{CH}_{3}$ groups in the phosphate deposit into - OH groups, transforming dimethylphosphinic acid into methylphosphinic acid or possibly phosphoric acid. As many metal precursors (e.g. TMA) need $-\mathrm{OH}$ groups to chemisorb on, this not only removes unwanted carbon but also enhances the reaction of the organophosphate layer with a metal precursor to form a metal phosphate. In other words, a phosphorus source is formed "in-situ" on the sample surface, ready to accept a metal source.

\section{Growth of aluminium phosphate}

In what follows, we will focus on a three-step process to grow aluminium phosphate by combining TMP plasma and $\mathrm{O}_{2}$ plasma with a third step in the form of a TMA exposure. As opposed to the films deposited by TMP plasma or TMP $/ \mathrm{O}_{2}$ plasma alone, which degraded after removal from the reactor, the [TMP plasma - $\mathrm{O}_{2}$ plasma - TMA] process resulted in the growth of aluminium phosphate films which remained stable in an ambient atmosphere.

Figure 7 shows the growth per cycle of this process as a function of the deposition temperature. It can be compared to figure 4, the only difference being the inclusion of an $\mathrm{O}_{2}$ plasma and TMA pulse after each TMP plasma pulse. The TMP plasma pulse durations were set to $3 \mathrm{~s}$ for curve (a) and $10 \mathrm{~s}$ for curve (b), while the $\mathrm{O}_{2}$ plasma pulse and TMA pulse durations were fixed to $3 \mathrm{~s}$ each in both cases. GPC values were determined from the slopes of in-situ ellipsometry growth curves, as shown in the inset of figure 7. All layers satisfied a single Cauchy dispersion relation $n(\lambda)=1.511+3.00 \times 10^{-3} \mu \mathrm{m}^{2} / \lambda^{2}+5.50 \times 10^{-5} \mu \mathrm{m}^{4} / \lambda^{4}$, which yields a refractive index of 1.52 at a wavelength of $589 \mathrm{~nm}$. At low temperatures $\left(<100{ }^{\circ} \mathrm{C}\right)$, curve (b) shows a significantly higher GPC than curve (a). This should not come as a surprise: at low temperatures, TMP plasma polymerizes at a high rate, and 
extending the pulse duration significantly increases the total amount of deposited material (i.e. the $\mathrm{GPC}$ ) and also the $\mathrm{P} / \mathrm{Al}$ ratio (numbers in gray). At the high-temperature side $\left(>300{ }^{\circ} \mathrm{C}\right)$, however, something remarkable happens: material still gets deposited at a rate of 4 to $5 \AA$ /cycle, even though the polymerization of TMP plasma is inhibited (as seen in figure 4). Additionally, the GPC of curve (b) is only slightly higher than for curve (a), despite the three-fold increase in TMP plasma duration, and the $\mathrm{P} / \mathrm{Al}$ ratios are similar. We are lead to the conclusion that this process must be split up in two regimes: a low-temperature regime characterized by continuous and unsaturated growth (plasma-enhanced CVD), and a high-temperature regime characterized by saturated growth where individual TMP plasma pulses do not result in deposition but sequential exposures with $\mathrm{O}_{2}$ plasma and TMA vapor do. We therefore regard this high-temperature regime as plasma-enhanced ALD. The fact that TMP polymerization is no longer temperature-inhibited when TMA pulses are included might be caused by an increased tendency to form chemical bonds on the surface, i.e. the reaction enthalpy is more negative by the presence of TMA on the sample surface, which shifts the ceiling temperature upwards.

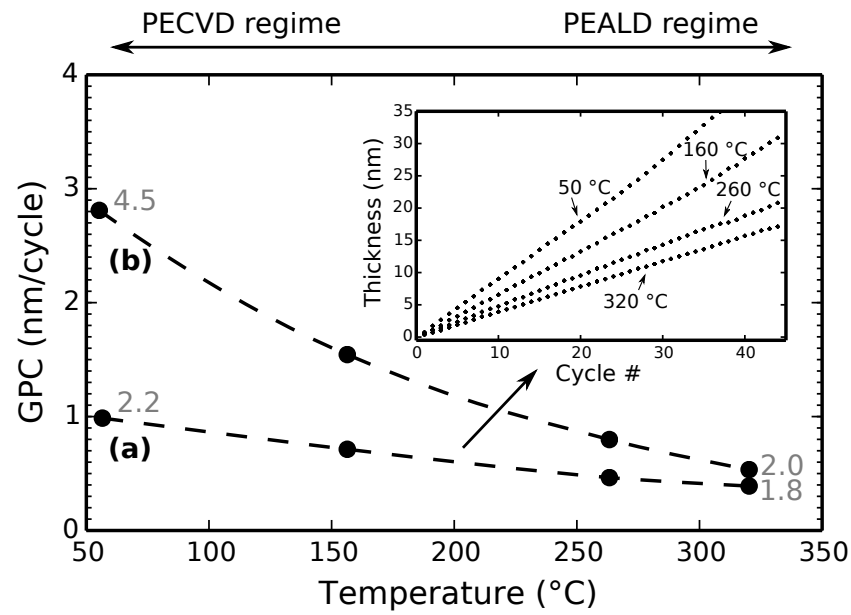

Figure 7: The growth per cycle as a function of the deposition temperature for two sequences: (a) [3 s TMP plasma - 3 $\mathrm{s} \mathrm{O}_{2}$ plasma - 3 s TMA] and (b) [10 s TMP plasma - $3 \mathrm{~s} \mathrm{O}_{2}$ plasma - $3 \mathrm{~s}$ TMA]. Inset: growth curves measured by in-situ ellipsometry for (a), showing linear growth (similar for (b)). Numbers in gray represent the $\mathrm{P} / \mathrm{Al}$ ratios of certain samples determined from XPS analysis. 
The influence of the TMA pulse duration on the GPC was investigated for the same process in both low-temperature (PECVD) and high-temperature (PEALD) regimes. The results are shown in figure 8. The GPC does not depend on the TMA pulse duration if the duration is $1 \mathrm{~s}$ or longer, and this holds for both regimes, although with very different values. In the low-temperature regime, the saturated GPC value (i.e. for for $\geq 1 \mathrm{~s}$ TMA) is about $2.8 \mathrm{~nm} /$ cycle and the one for $0 \mathrm{~s}$ TMA (i.e. for the [TMP plasma - $\mathrm{O}_{2}$ plasma] process) is even higher than that. This might be because the aluminium-containing layers are denser and thus have a lower thickness for the same amount of material. In the high-temperature regime, the GPC is close to zero in the absence of TMA pulses (as previously discussed) and assumes a value of $5.5 \AA$ /cycle for TMA durations of $1 \mathrm{~s}$ or longer. Additionally, $\mathrm{P} / \mathrm{Al}$ ratios derived from XPS analysis are independent of the TMA pulse duration. These observations suggest saturation during the TMA exposure step.

\section{Unraveling the reaction mechanism}

In order to better understand how this deposition process works, the reaction products were analyzed by multiple ion detection mass spectrometry. In figure 9 , two species were monitored: $\mathrm{PO}$ at $\mathrm{m} / \mathrm{z}=47$ (a fragment of TMP, as can be seen in figure 3, chosen to track

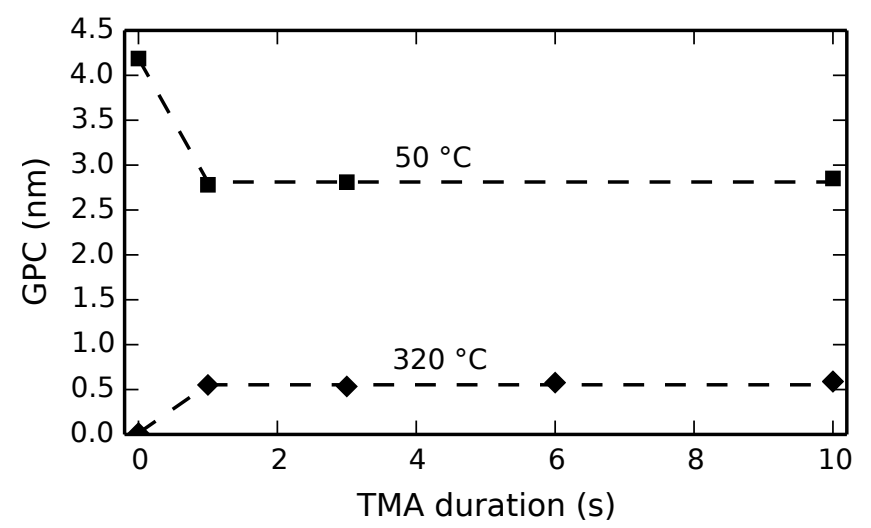

Figure 8: Growth per cycle of the [TMP plasma - $\mathrm{O}_{2}$ plasma - TMA] process as a function of the TMA pulse duration, showing saturated behavior in both the PECVD temperature regime $\left(50{ }^{\circ} \mathrm{C}\right.$, upper curve $)$ and the PEALD regime $\left(320^{\circ} \mathrm{C}\right.$, lower curve). The TMP plasma and $\mathrm{O}_{2}$ plasma pulse times were fixed to resp. $10 \mathrm{~s}$ and $3 \mathrm{~s}$. 
the TMP pulses) and $\mathrm{CH}_{4}$ /oxygen at $\mathrm{m} / \mathrm{z}=16$ (chosen because methane is released when TMA reacts with hydroxyl surface groups). The substrate temperature was set to $150{ }^{\circ} \mathrm{C}$. However, as the reaction products may originate from all over the deposition chamber and the chamber walls comprise most of the inner surface area, we assume that the reaction products mainly originate from deposition on the chamber walls at a temperature of $95{ }^{\circ} \mathrm{C}$. In both cases, the reactions happen in the PECVD temperature regime.

In figure 9a, the [TMP plasma - $\mathrm{O}_{2}$ plasma - TMA] process was studied. During the TMP plasma discharge, both PO and oxygen were present, as previously discussed and shown in figure 3. During the subsequent oxygen plasma step, only oxygen was visible. When TMA was introduced, a sharp spike in the channel at $\mathrm{m} / \mathrm{z}=16$ was observed. This signal is very similar to what is observed in the well-known TMA-water process (figure 9f) where $\mathrm{Al}_{2} \mathrm{O}_{3}$ is grown and $\mathrm{CH}_{4}$ is produced as a reaction product. This provides experimental evidence that TMA reacts with $-\mathrm{OH}$ groups in the organophosphate layer created by the TMP and

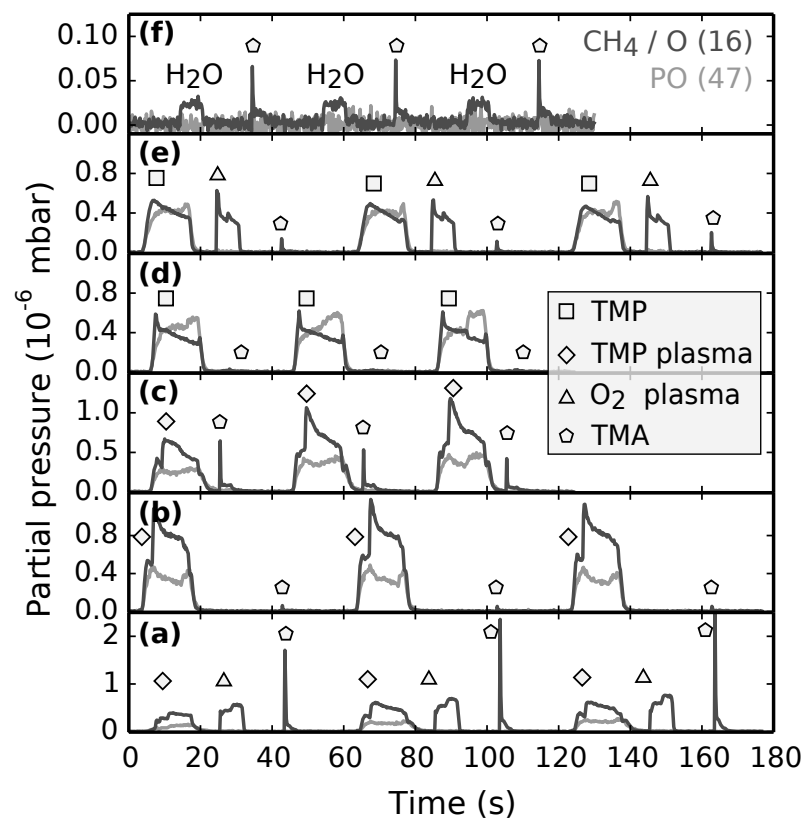

Figure 9: Multiple ion detection mass spectrometry during five different variations on the [TMP plasma - $\mathrm{O}_{2}$ plasma - TMA] process and one standard [TMA - $\mathrm{H}_{2} \mathrm{O}$ ] process for reference purposes. Dark gray: $\mathrm{CH}_{4}$ /oxygen signal at $\mathrm{m} / \mathrm{z}=16$. Light gray: $\mathrm{PO}$ signal (TMP fragment) at $\mathrm{m} / \mathrm{z}=47$. 
$\mathrm{O}_{2}$ plasma exposures and forms $\mathrm{CH}_{4}$ as a byproduct:

$$
-\mathrm{OH}+\mathrm{Al}\left(\mathrm{CH}_{3}\right)_{3} \longrightarrow-\mathrm{O}-\mathrm{Al}\left(\mathrm{CH}_{2}\right)_{2}+\mathrm{CH}_{4}
$$

In figure 9b, the oxygen plasma step was skipped, resulting in a [TMP plasma - TMA] process. The $\mathrm{CH}_{4}$ spike while pulsing TMA is still present, but is much lower in magnitude. However, as can be seen in figure 9c, when TMA is pulsed immediately after the TMP plasma, the spike increases in magnitude again. This might indicate dehydration of the organophosphate layer over time. In figure 9d, TMP vapor was used instead of TMP plasma; no methane spike was visible, supporting our observation that the [TMP vapor - TMA] process does not grow anything due to lack of a chemical reaction. However, by adding an intermediate oxygen plasma, as was done in figure 9e, a (weak) methane spike is again observed; this process resembles the one by Liu et $\mathrm{al}^{8}$ and grows material very slowly.

Figure 10 focuses on the [TMP plasma - $\mathrm{O}_{2}$ plasma - TMA] process as in figure 9a but provides additional channels. Figure $10 \mathrm{~b}$ shows $\mathrm{CH}_{3}$ at $\mathrm{m} / \mathrm{z}=15$, which is prominent

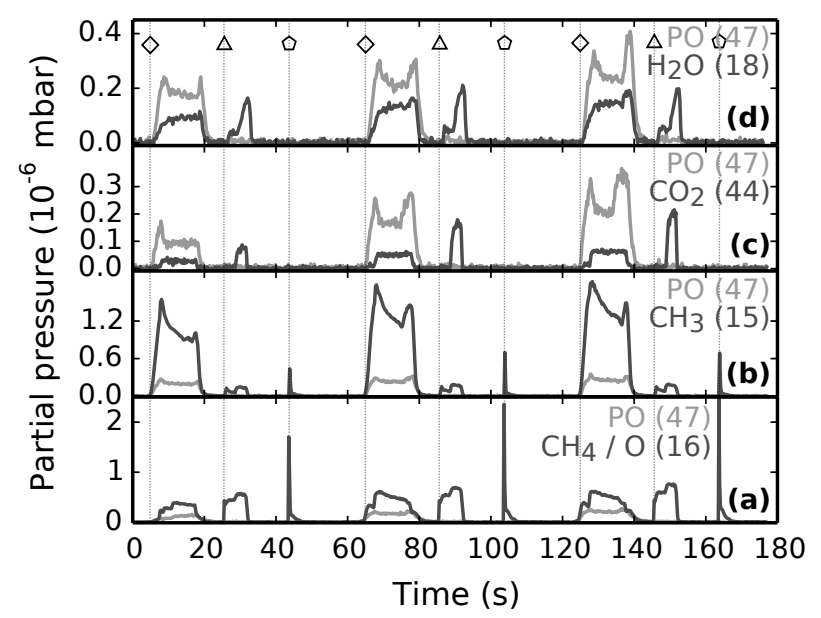

Figure 10: Multiple ion detection mass spectrometry of the [TMP plasma - $\mathrm{O}_{2}$ plasma TMA] process (designated by resp. diamonds, triangles and pentagons, same as in figure 9a), monitoring additional species. The PO signal (TMP fragment) at $\mathrm{m} / \mathrm{z}=47$ is shown throughout, in addition to (from top to bottom) (a) $\mathrm{H}_{2} \mathrm{O}$ at $\mathrm{m} / \mathrm{z}=18$, (b) $\mathrm{CO}_{2}$ at $\mathrm{m} / \mathrm{z}=44$, (c) $\mathrm{CH}_{3}$ at $\mathrm{m} / \mathrm{z}=15$ and (d) $\mathrm{CH}_{4}$ /oxygen at $\mathrm{m} / \mathrm{z}=16$. 
during the TMP plasma (as can be seen in figure 3) and spikes simultaneously with the methane channel. A weak signal can also be observed during the oxygen plasma pulse; this is probably the result of instrumental bleed from the adjacent oxygen channel. Figures 10c and $10 \mathrm{~d}$ respectively show $\mathrm{CO}_{2}$ at $\mathrm{m} / \mathrm{z}=44$ and $\mathrm{H}_{2} \mathrm{O}$ at $\mathrm{m} / \mathrm{z}=18$. Both of them are formed during the TMP plasma (as previously noted) and during the oxygen plasma, while they are absent during the TMA pulse. Their presence during the oxygen plasma, coupled with the observation that the amount of carbon in the organophosphate layers is reduced, suggests that the $\mathrm{O}_{2}$ plasma removes methyl ligands in the organophosphate layer by a combustion reaction:

$$
-\mathrm{O}-\mathrm{CH}_{3}+3 \mathrm{O} \cdot \longrightarrow-\mathrm{OH}+\mathrm{CO}_{2}+\mathrm{H}_{2} \mathrm{O}
$$

The surface chemistry during the $\left[\mathrm{TMP}\right.$ plasma $-\mathrm{O}_{2}$ plasma - TMA] process was also investigated by in-situ infrared spectroscopy. The substrate temperature was held at $150{ }^{\circ} \mathrm{C}$; spectra were acquired after each substep, and this was repeated during 50 cycles. The results are shown in figure 11, wherein the total absorption spectrum of the deposited film is plotted along with difference spectra after each substep. Each difference spectrum was averaged over 50 cycles in order to minimize noise contributions. The absorption spectrum equals the sum of the three difference spectra, as the absorption of the substrate was already subtracted.

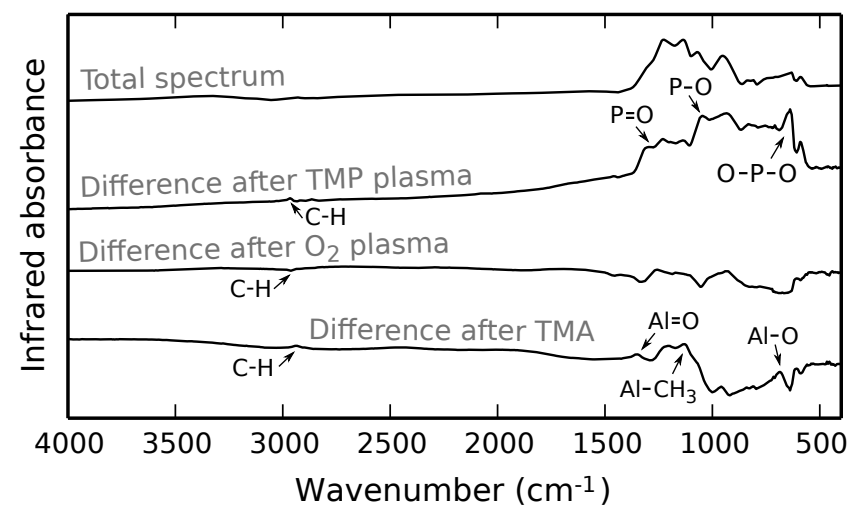

Figure 11: In-situ infrared spectroscopy during the [TMP plasma - $\mathrm{O}_{2}$ plasma - TMA] process at $150{ }^{\circ} \mathrm{C}$. The upper curve shows the infrared absorption spectrum of the aluminium phosphate film after 50 cycles. The three curves below it are difference spectra after each substep, each one averaged over 50 cycles to improve the signal/noise ratio. 
The difference spectrum after the TMP plasma shows a $\mathrm{C}-\mathrm{H}$ stretch at $2960 \mathrm{~cm}^{-1}, \mathrm{P}=\mathrm{O}$ stretching vibrations around $1300 \mathrm{~cm}^{-1}, \mathrm{P}-\mathrm{O}$ stretching vibrations around $1050 \mathrm{~cm}^{-1}$ and $\mathrm{O}-\mathrm{P}-\mathrm{O}$ bending vibrations around $600 \mathrm{~cm}^{-1} \cdot 2,18,24,25$ This demonstrates the formation of (poly)phosphate groups by exposure to the TMP plasma. The $\mathrm{O}_{2}$ plasma difference spectrum shows a small valley at the exact location of the TMP plasma $\mathrm{C}-\mathrm{H}$ stretch; this implies that carbon is being removed by $\mathrm{O}_{2}$ plasma, in accordance with previous observations. A number of other valleys can be seen between 1500 and $500 \mathrm{~cm}^{-1}$; these are supposedly also related to the removal of carbon-containing bonds, although their exact attribution is unclear. The difference spectrum associated with the TMA pulse shows a $\mathrm{C}-\mathrm{H}$ stretch at $2940 \mathrm{~cm}^{-1}$ due to the methyl ligands which remain around each aluminium atom. Additionally, $\mathrm{Al}=\mathrm{O}$ and $\mathrm{Al}-\mathrm{O}$ stretch bands ${ }^{26}$ could be identified at resp. $1350 \mathrm{~cm}^{-1}$ and $700 \mathrm{~cm}^{-1}$.

To summarize, the information above leads us to the following picture of the deposition process:

- Through plasma polymerization of the TMP precursor, a surface organophosphate layer is grown, its chemical structure being similar to TMP albeit with some methyl groups getting replaced by hydroxyl groups.

- By exposure to $\mathrm{O}_{2}$ plasma, additional methyl groups in the surface layer are replaced by hydroxyl groups. The resulting chemical structure is presumably more similar to phosphoric acid than to the original TMP molecule. One could state that the plasma induces the in-situ synthesis of a suitable phosphorus precursor on the substrate surface, thereby circumventing the impossibility of bringing phosphoric acid into the vapor phase.

- TMA now chemisorbs on the surface because its methyl ligands react with hydroxyl groups, creating $\mathrm{Al}-\mathrm{O}$ bonds and resulting in the formation of aluminium phosphate. 


\section{PEALD film properties}

Films were deposited at $320{ }^{\circ} \mathrm{C}$ using the [TMP plasma - $\mathrm{O}_{2}$ plasma - TMA] process with 3 s pulse times in order to characterize them by XPS, ERD and in-situ XRD.

The XPS analysis of an $18.5 \mathrm{~nm}$ aluminium phosphate film deposited under these conditions is shown in figure 12. The figure shows two survey spectra: the lower one (shown in light gray) was directly measured on the sample surface, while the upper one (shown in dark gray) was acquired after slightly sputtering away the surface (20 s at $3 \mathrm{keV}$ and $2 \mu \mathrm{A})$. Both spectra show the presence of aluminium, oxygen and phosphorus. Coupled with the lack of a silicon substrate signal, this confirms the realization of a closed aluminium phosphate layer. Carbon could only be detected on the film surface, but not after sputtering; this suggests that the layer is free from carbon contamination, with the surface carbon originating from exposure of the sample to the ambient atmosphere.

High-resolution measurements of the $\mathrm{Al} 2 \mathrm{p}, \mathrm{P} 2 \mathrm{p}, \mathrm{O} 1 \mathrm{~s}$ and $\mathrm{C} 1$ s surface regions were additionally made for quantification and chemical identification purposes. For each region, a Shirley-type background was subtracted and a Gaussian/Lorentzian peak shape was fitted. All peak locations were then shifted downwards by $2.7 \mathrm{eV}$ to bring the adventitious carbon peak to its reference energy of $284.8 \mathrm{eV}$. The resulting peak locations are shown in table 2 ,

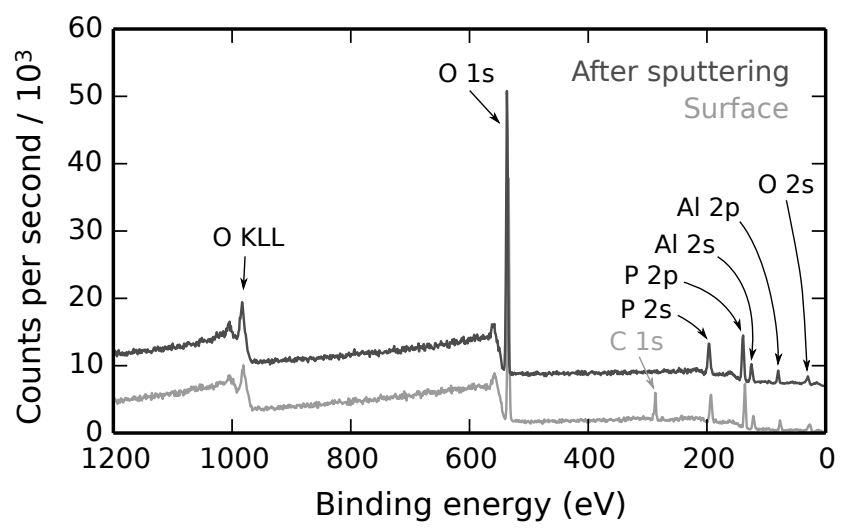

Figure 12: XPS survey spectrum of an $18.5 \mathrm{~nm}$ aluminium phosphate film grown at $320{ }^{\circ} \mathrm{C}$ for 50 cycles, indicating the presence of aluminium, oxygen and phosphorus throughout the film while carbon is only present on the surface. 
along with the atomic percentages of $\mathrm{Al}, \mathrm{P}, \mathrm{O}$ and $\mathrm{C}$. These were calculated from the surface areas under each peak, making use of tabulated sensitivity factors. A sample deposited under these conditions was also quantified by elastic recoil detection (ERD) analysis, of which the results are also shown in table 2. Finally, the theoretical amounts of aluminium, phosphorus, oxygen are included for two possible types of aluminium phosphate, namely aluminium orthophosphate $\left(\mathrm{AlPO}_{4}\right)$ and aluminium pyrophosphate $\left(\mathrm{Al}_{4} \mathrm{P}_{6} \mathrm{O}_{21}\right)$. The main difference between them is the $\mathrm{P} / \mathrm{Al}$ ratio, which is unity in the former case and 1.5 in the latter.

The chemical shifts are in agreement with the ones expected for an aluminophosphate material. ${ }^{27}$ The XPS surface measurement shows a considerable amount of carbon; after etching away some surface material, the remaining amount of carbon is below the detection limit of about $1 \%$, the $\mathrm{P} / \mathrm{Al}$ ratio is 1.8 and the atomic percentage of oxygen is $57 \%$. The ERD analysis (which is more accurate, generally to within $\pm 1 \%$ ) shows a $\mathrm{P} / \mathrm{Al}$ ratio of 1.8 , and $2.2 \%$ of carbon impurities. We conclude that this layer mainly consists of aluminium pyrophosphate, although still with some excess phosphorus.

A thick film (400 cycles, resulting in a layer thickness of about $150 \mathrm{~nm}$ ) was grown to study its crystallinity by in-situ X-ray diffraction (XRD) during annealing in a helium

Table 2: XPS peak positions measured on the deposited aluminium phosphate film, together with theoretical and measured atomic percentages of aluminium, phosphorus, oxygen and carbon determined by XPS and ERD.

\begin{tabular}{lllll}
\hline \hline Peak position $(\mathrm{eV})$ & $\mathrm{Al} 2 \mathrm{p}$ & $\mathrm{P} 2 \mathrm{p}$ & $\mathrm{O} 1 \mathrm{~s}$ & $\mathrm{C} 1 \mathrm{~s}$ \\
\hline \hline Material & 74.4 & 133.9 & 531.6 & 284.8 \\
\hline $\mathrm{AlPO}_{4}$ & $\% \mathrm{Al}$ & $\% \mathrm{P}$ & $\% \mathrm{O}$ & $\% \mathrm{C}$ \\
$\mathrm{Al}_{4} \mathrm{P}_{6} \mathrm{O}_{21}$ & 16.7 & 16.7 & 66.7 & 0 \\
\hline \hline Measurement & 12.9 & 19.4 & 67.7 & 0 \\
\hline XPS (surface) & 11.8 & 23.0 & 50.0 & 15.3 \\
XPS (sputtered) & 15.5 & 27.5 & 57.0 & $<1$ \\
ERD & 11.3 & 20.2 & 67.8 & 2.2 \\
\hline \hline
\end{tabular}


atmosphere. Figure 13 shows the diffraction pattern (color mapping: higher intensities are lighter) and the temperature (dashed white line) as a function of time during a linear ramp up to $1050{ }^{\circ} \mathrm{C}$ at $12{ }^{\circ} \mathrm{C} / \mathrm{min}$. The material starts off amorphous, but three distinct diffraction peaks appear when the temperature approaches $900{ }^{\circ} \mathrm{C}$. These are more easily visible in figure 14, where the XRD patterns before and after annealing have been plotted in a more conventional way. The observed diffraction pattern after crystallization corresponds to triclinic $\mathrm{AlPO}_{4}$ tridymite. ${ }^{28}$

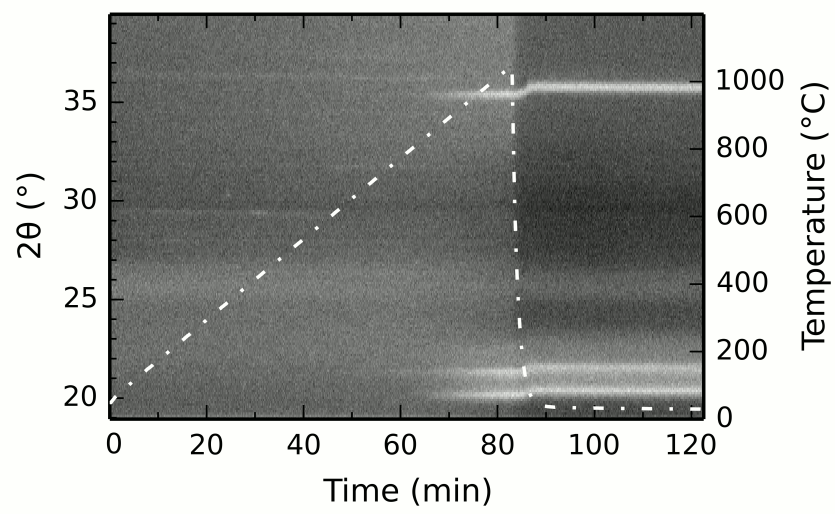

Figure 13: In-situ XRD measurement of the aluminium phosphate film while applying a linear temperature ramp from room temperature to $1050{ }^{\circ} \mathrm{C}$ at $12{ }^{\circ} \mathrm{C} / \mathrm{min}$ in a He atmosphere. The as-deposited material is amorphous, but becomes crystalline upon heating to around $900{ }^{\circ} \mathrm{C}$.

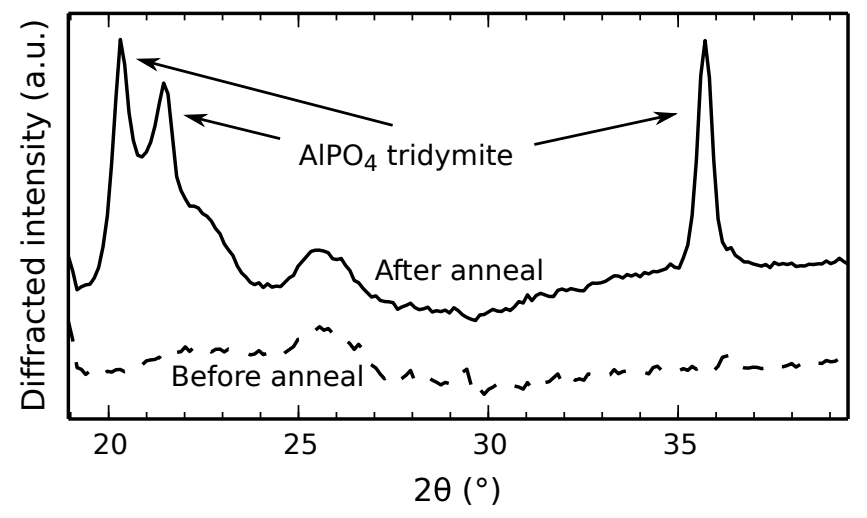

Figure 14: XRD patterns measured at room temperature before and after annealing for the same aluminium phosphate film as in figure 13. The pattern before annealing only shows an amorphous background, while the one after annealing shows clear diffraction peaks corresponding to triclinic $\mathrm{AlPO}_{4}$ tridymite. 


\section{Conclusions}

We demonstrated the layer-by-layer growth of aluminium phosphate by exploiting the polymerization properties of an inductively coupled trimethyl phosphate plasma. The plasma was shown to contain excited hydrogen and oxygen atoms and produced hydrogen gas in addition to hydrocarbons, oxygen and $\mathrm{CO}_{2}$, indicating that chemical bonds in the TMP molecule were being broken and reconfigured. At low temperatures, the TMP plasma polymerized at a high rate and continuously grew an organophosphate layer; at temperatures above $300{ }^{\circ} \mathrm{C}$, this process was inhibited. The addition of subsequent $\mathrm{O}_{2}$ plasma and TMA pulses resulted in the growth of aluminium phosphate, likewise showing a strong temperature dependency. We distinguished a low-temperature PECVD regime, where the growth per cycle and the $\mathrm{P} / \mathrm{Al}$ ratio increased with the TMP plasma duration, and a high-temperature PEALD regime, where they saturated. The TMP plasma and $\mathrm{O}_{2}$ plasma steps resulted in the formation of a phosphorus-containing surface which contained hydroxyl groups and readily reacted with an organometallic precursor such as TMA to form aluminium-oxygen bonds. Saturation with regard to the TMA exposure was found in both temperature regimes, backed by the observation of short $\mathrm{CH}_{4}$ spikes when TMA was pulsed. The resulting films consisted of slightly phosphorus-rich aluminium pyrophosphate; crystalline aluminium orthophosphate was formed by annealing above $900{ }^{\circ} \mathrm{C}$.

\section{Acknowledgement}

The authors are grateful to the FWO Vlaanderen for providing Thomas Dobbelaere with financial support through the mandate of Aspirant, and for financial support from the ERANET, UGENT-GOA-01G01513, IWT-SBO SOSLion and LaminaLion projects. They also

thank Kilian Devloo-Casier and Matthias Minjauw for the XPS measurements, Elisabeth Levreau for advice on FTIR, Olivier Janssens for SEM/EDX work and Brecht Put for arranging ERD analysis at imec. 


\section{References}

(1) Miikkulainen, V.; Leskelä, M.; Ritala, M.; Puurunen, R. L. Journal of Applied Physics 2013, 113, 021301.

(2) Nieminen, M.; Niinistö, L.; Lappalainen, R. Microchimica Acta 1995, 119, 13-22.

(3) Tiitta, M.; Nykänen, E.; Soininen, P.; Niinistö, L.; Leskelä, M.; Lappalainen, R. Materials Research Bulletin 1998, 33, 1315-1323.

(4) Putkonen, M.; Sajavaara, T.; Rahkila, P.; Xu, L.; Cheng, S.; Niinistö, L.; Whitlow, H. J. Thin Solid Films 2009, 517, 5819-5824.

(5) Hämäläinen, J.; Holopainen, J.; Munnik, F.; Hatanpää, T.; Heikkilä, M.; Ritala, M.; Leskelä, M. Journal of The Electrochemical Society 2012, 159, A259-A263.

(6) Wiedmann, M. K.; Jackson, D. H. K.; Pagan-Torres, Y. J.; Cho, E.; Dumesic, J. A.; Kuech, T. F. Journal of Vacuum Science \& Technology A 2012, 30, 01A134.

(7) Hämäläinen, J.; Holopainen, J.; Munnik, F.; Heikkilä, M.; Ritala, M.; Leskelä, M. The Journal of Physical Chemistry C 2012, 116, 5920-5925.

(8) Liu, J.; Tang, Y.; Xiao, B.; Sham, T.-K.; Li, R.; Sun, X. RSC Advances 2013, 3, 4492-4495.

(9) Knohl, S.; Roy, A. K.; Lungwitz, R.; Spange, S.; Mäder, T.; Nestler, D. J.; Wielage, B.; Schulze, S.; Hietschold, M.; Wulff, H.; Helm, C. A.; Seidel, F.; Zahn, D. R. T.; Goedel, W. A. ACS Applied Materials \& Interfaces 2013, 5, 6161-6167.

(10) Gandrud, K. B.; Pettersen, A.; Nilsen, O.; Fjellvåg, H. Journal of Materials Chemistry A 2013, 1, 9054-9059.

(11) Sønsteby, H. H.; Østreng, E.; Fjellvåg, H.; Nilsen, O. Chemical Vapor Deposition 2014, 20, 269-273. 
(12) Kim, B.; Kim, C.; Kim, T.-G.; Ahn, D.; Park, B. Journal of The Electrochemical Society 2006, 153, A1773-A1777.

(13) Meyers, S. T.; Anderson, J. T.; Hong, D.; Hung, C. M.; Wager, J. F.; Keszler, D. A. Chemistry of Materials 2007, 19, 4023-4029.

(14) Alberti, G.; Cardini-Galli, P.; Costantino, U.; Torracca, E. Journal of Inorganic and Nuclear Chemistry 1967, 29, 571-578.

(15) Clearfield, A.; Thakur, D. S. Applied Catalysis 1986, 26, 1-26.

(16) Kuwata, N.; Iwagami, N.; Tanji, Y.; Matsuda, Y.; Kawamura, J. Journal of The Electrochemical Society 2010, 15\%, A521-A527.

(17) Stull, D. R. Industrial \& Engineering Chemistry 1947, 39, 517-540.

(18) Hilt, F.; Duday, D.; Gherardi, N.; Frache, G.; Bardon, J.; Choquet, P. Plasma Processes and Polymers 2013, 10, 556-563.

(19) Zhang, J.-G.; Meda, L.; Maxie, E. System and method of producing thin-film electrolyte. 2005; U.S. Classification 29/623.5, 423/306, 429/162, 429/322; International Classification C23C16/30, C23C16/513, H01M10/36, H01M10/0562, H01M10/052; Cooperative Classification C23C16/513, H01M10/052, Y02E60/122, C23C16/30, H01M10/0562; European Classification C23C16/513, C23C16/30, H01M10/052, H01M10/0562.

(20) Yasuda, H. K. Plasma Polymerization; Academic Press: London, 1985.

(21) Reva, I.; Simo, A.; Fausto, R. Chemical Physics Letters 2005, 406, 126-136.

(22) George, L.; Sankaran, K.; Viswanathan, K. S.; Mathews, C. K. Applied Spectroscopy 1994, 48, 7-12. 
(23) Tokhadze, K. G.; Denisov, G. S.; Wierzejewska, M.; Drozd, M. Journal of Molecular Structure 1997, 404, 55-62.

(24) Nakamoto, K. Infrared and Raman Spectra of Inorganic and Coordination Compounds, 3rd Ed.; Wiley: New York, 1978; pp 172-173.

(25) Campelo, J. M.; Marinas, J. M.; Mendioroz, S.; Pajares, J. A. Journal of Catalysis 1986, 101, 484-495.

(26) Katz-Tsameret, Z.; Raveh, A. Journal of Vacuum Science \&3 Technology A 1995, 13, $1121-1127$.

(27) Zahedi-Niaki, M. H.; Joshi, P. N.; Kaliaguine, S. Chemical Communications 1996, $1373-1374$.

(28) Graetsch, H. Acta Crystallographica Section C: Crystal Structure Communications 2000, 56, 401-403. 


\section{Graphical TOC Entry}

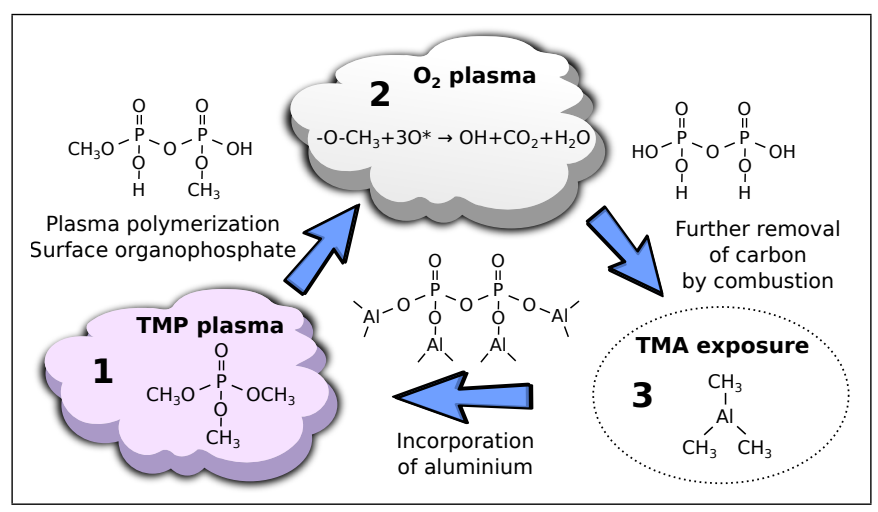

